BRANDÃO FILHO, J.U.T.; GOTO, R.; GUIMARÃES, V.F.; HABERMANN, G.; RODRIGUES, J.D.; CALLEGARI, O. Influência da enxertia nas trocas gasosas de dois híbridos de berinjela cultivados em ambiente protegido. Horticultura Brasileira, Brasília, v.21, n. 3, p. 474-477, julho-setembro 2003.

\title{
Influência da enxertia nas trocas gasosas de dois híbridos de berinjela cultivados em ambiente protegido
}

\author{
José Usan T. Brandão Filho ${ }^{1}$; Rumy Goto ${ }^{2}$; Vandeir Francisco Guimarães ${ }^{3}$; Gustavo Habermann ${ }^{3}$; João \\ D. Rodrigues ${ }^{3}$; Osni Callegari ${ }^{1}$ \\ ${ }^{1}$ UEM, Depto. Agronomia, Av. Colombo, 5790, 87020-900 Maringá-PR; E-mail: jutbfilho@uem.br; ${ }^{2 U N E S P, ~ D e p t o . ~ P r o d u c ̧ a ̃ o ~ V e g e t a l, ~}$ \\ C. Postal 237, 18603-970 Botucatu-SP; ${ }^{3}$ UNESP, Depto. Botânica, C. Postal 510, 18618-000 Botucatu-SP
}

\begin{abstract}
RESUMO
Compararam-se os efeitos da enxertia nas trocas gasosas de dois híbridos de berinjela em pé franco e enxertado. Conduziu-se um ensaio em ambiente protegido, na FCA/UNESP, em estrutura simples, tipo arco com $7 \mathrm{~m}$ de largura, $40 \mathrm{~m}$ de comprimento e $3 \mathrm{~m}$ de pé direito, cobertos por filme plástico de 100 micrometros. Foram utilizados os híbridos de berinjela Nápoli e Kokuyo, enxertados em portaenxerto específico (híbrido Taibyo VF) para esta espécie. O delineamento experimental utilizado foi inteiramente casualizado, com quatro tratamentos (Nápoli pé franco, Nápoli enxertada, Kokuyo pé franco e Kokuyo enxertada) com dez repetições. A assimilação líquida de $\mathrm{CO}_{2}(\mathrm{~A})$, transpiração $(\mathrm{E})$, condutância estomática $\left(\mathrm{g}_{\mathrm{s}}\right)$ e eficiência no uso de água (EUA), obtida pela relação $(\mathrm{A} / \mathrm{E})$, foram determinadas às 09:00; 12:00; 14:00 e 16:00 horas em um dia sem nebulosidade com fluxo de fótons fotossinteticamente ativos (FFFA) de $937 \pm 126 \mathrm{mmol}$ $\mathrm{m}^{-2} \mathrm{~s}^{-1}$, com um sistema fechado portátil de fotossíntese, IRGA, modelo LI-6200 (LI-COR). Observou-se que as plantas do híbrido Kokuyo apresentaram maiores valores para as variáveis $\mathrm{A}, \mathrm{E}, \mathrm{g}_{\mathrm{s}}$ e EUA que o híbrido Nápoli. A enxertia não afetou a capacidade fotossintética dos híbridos, porém, esta resultou em menores valores de $\mathrm{E}$ e $\mathrm{g}_{\mathrm{s}}$ nos dois híbridos, levando à maior EUA, efeito este que na prática pode resultar em menor demanda de água pelas plantas.
\end{abstract}

Palavras-chave: Solanum melongena L., fotossíntese, transpiração, híbridos.

\begin{abstract}
Grafting effect on leaf gas exchange rates of two eggplant hybrids cultivated in greenhouse

Leaf gas exchange rates of grafted and non-grafted eggplant hybrids were compared under greenhouse conditions. The experiment was conducted in a plastic house ( $7 \mathrm{~m}$ in width, $40 \mathrm{~m}$ in length and $3 \mathrm{~m}$ in height), covered with 100 micrometros plastic film. Hybrids Napoli and Kokuyo were grafted on the Taibyo VF hybrid, a specific rootstock for eggplant grafting. The experimental design was a completely randomized design with four treatments (non-grafted Napoli hybrid; grafted Napoli hybrid; non-grafted Kokuyo hybrid and grafted Kokuyo hybrid) and ten replications. Net $\mathrm{CO}_{2}$ assimilation (A) and transpiration (E) rates, stomatal conductance $\left(\mathrm{g}_{\mathrm{s}}\right)$ and water use efficiency (EUA) were measured at 09:00; 12:00; 14:00 and 16:00 h on a non-cloudy day with photosynthetic active radiation (PAR) of $937 \pm 126 \mathrm{mmol} \mathrm{m}^{-}$ ${ }^{2} \mathrm{~s}^{-1}$, with a close photosynthesis system, IRGA, LI-6200 (LI-COR). Results showed that Kokuyo hybrid presented greater A, E, $g_{s}$ and EUA when compared to Napoli hybrid. None of the hybrid's photosynthetic capacities were affected by the grafting, but the same caused lower $\mathrm{E}$ and $\mathrm{g}_{\mathrm{s}}$ on both hybrids, leading to greater EUA, which in practice may result in less water demand.
\end{abstract}

Keywords: Solanum melongena L., photosynthesis, transpiration, hybrid.

(Recebido para publicação em 06 de fevereiro de 2002 e aceito em 18 de junho de 2003)

\begin{abstract}
$\mathrm{A}$ produção em ambiente protegido apresenta-se como alternativa para o produtor, em uma economia competitiva, uma vez que permite redução de perdas e aumento da produtividade de diversas culturas. Entretanto vários são os casos de insucesso, levando muitos agricultores a abandonarem a atividade após algum tempo. Desde o início do cultivo protegido no Brasil, as hortaliças mais utilizadas são o pimentão, alface, tomate e pepino. Entretanto, nos últimos anos, algumas culturas vêm ganhando destaque. Dentre estas a berinjela (Solanum melongena L.), cultura pouco estudada sob plasticultura, vem despertando interesse por suas propriedades nutracêuticas, existindo evidências de sua ação na redução do colesterol
\end{abstract}

no organismo humano (Santos et al., 2000).

O uso intensivo do solo, seu manejo inadequado e a utilização inadequada de adubos, vêm resultando em solos com sérios problemas fitossanitários nutricionais. Uma das alternativas para solucionar estes problemas é a possibilidade de enxertia em porta-enxertos resistentes ou tolerantes. Segundo Kobori (1999) esta prática vem sendo utilizada em pimentão para obtenção de frutos de melhor qualidade, maior produtividade e adaptação a temperaturas adversas, além do controle de doenças de solo. A enxertia em berinjela vem ganhando destaque nos últimos anos, principalmente nos países asiáticos e europeus. Oda (1995) relatou que, em campo aberto, $43 \%$ das berinjelas são enxertadas e $95 \%$ no cultivo protegido, totalizando cerca de $50 \%$ da berinjela plantada no Japão.

Oda (1995), trabalhando com o portaenxerto híbrido Taibyo VF para a berinjela, enumera as suas principais vantagens: controle de murcha-bacteriana (Ralstonia solanacearum), murcha-de-verticílio (Verticillium dahliae), murcha-de-fusário (Fusarium oxysporum), tolerância às baixas temperaturas, nematóides e aumento do vigor da planta. Ohara et al. (1990) e Shishido et al. (1995), relataram as vantagens do porta-enxerto híbrido Taibyo VF (Solanum integrifolium x Solanum melongena), conseguindo resistência à murcha-de-verticílio e murcha-de-fusário, tolerância a temperaturas baixas e grande vigor. 
A produtividade é influenciada por características morfológicas e fisiológicas da fonte (órgãos fotossintetizantes) e do dreno (órgãos consumidores dos metabólitos fotossintetizados, carboidratos principalmente). Toda produção de fitomassa depende da atividade fotossintética da fonte, porém a assimilação do $\mathrm{CO}_{2}$ é apenas um dos muitos fatores que influenciam o crescimento e desenvolvimento vegetal (Foyer \& Galtier, 1996). Desta forma, buscar mais informações sobre a fisiologia da fonte torna-se de fundamental importância, e uma forma muito utilizada para estudá-la é por meio de medidas de trocas gasosas.

Kim \& Hori (1989), estudando a capacidade fotossintética das folhas de berinjela, mostraram valores máximos em torno de $22 \mathrm{mmol} \mathrm{CO} \mathrm{m}^{-2} \mathrm{~s}^{-1}$ e que as taxas fotossintéticas dependiam da idade das folhas e correlacionavam diretamente com o teor de clorofila das mesmas. Estes valores são considerados altos, levando em consideração que a berinjela é uma planta de ciclo $\mathrm{C}_{3}$ (Pimentel et al., 1995). Ikeda (1981) verificou que a taxa fotossintética de mudas de berinjela, tomate e pepino, também variava de acordo com o posicionamento da folha.

Deve-se destacar que, em estudos visando ganhos em produtividade, é importante buscar informações sobre assimilação de $\mathrm{CO}_{2}$, bem como sobre a eficiência do uso da água para esta assimilação. Pouco se tem estudado sobre trocas gasosas para esta cultura, principalmente relacionado à enxertia. Neste contexto, o presente trabalho objetivou comparar os efeitos da enxertia nas trocas gasosas de dois híbridos de berinjela, em pé franco e enxertadas, cultivadas em ambiente protegido.

\section{MATERIAL E MÉTODOS}

O experimento foi conduzido em ambiente protegido, em módulo de estrutura simples, tipo arco com $7 \mathrm{~m}$ de largura, $40 \mathrm{~m}$ de comprimento $\left(280 \mathrm{~m}^{2}\right)$ e $3 \mathrm{~m}$ de pé direito, cobertos por filme de polietileno de baixa densidade de 100 micrometros, na FCA/UNESP, campus de Botucatu. A área experimental está em altitude média de 750 metros, precipita- ção e temperatura média anual de 1530 mm e $21^{\circ} \mathrm{C}$, respectivamente, com um latossolo vermelho amarelo fase arenosa, textura média e relevo suave ondulado.

O solo foi preparo com implemento "picão canteirador 1.5 MAFES" que permitiu incorporação uniforme da vegetação e movimentação do solo a aproximadamente $50 \mathrm{~cm}$ de profundidade, em 02/08/99.

Os resultados da análise química do solo revelaram na Estrutura 1: $6,4 \mathrm{pH}_{\mathrm{CaCl} 2} ; 13 \mathrm{~g} \mathrm{dm}^{-3}$ matéria orgânica, $120 \mathrm{mg} \mathrm{dm}^{-3}$ de P; $1,1 \mathrm{mmol}_{\mathrm{c}} \mathrm{dm}^{-3} \mathrm{de} \mathrm{K}$; $52 \mathrm{mmol}_{\mathrm{c}} \mathrm{dm}^{-3}$ de $\mathrm{Ca} ; 11 \mathrm{mmol}_{\mathrm{c}} \mathrm{dm}^{-3} \mathrm{de}$ $\mathrm{Mg}$; e $11 \mathrm{mmol}_{\mathrm{c}} \mathrm{dm}^{-3} \mathrm{de} \mathrm{H}+\mathrm{Al} \mathrm{e} \mathrm{V \%} \mathrm{de}$ 86. Na Estrutura 2: $6,6 \mathrm{pH}_{\mathrm{CaCl} 2} ; 10 \mathrm{~g} \mathrm{dm}^{-3}$ matéria orgânica, $62 \mathrm{mg} \mathrm{dm}^{-3}$ de P; 0,8 mmol $\mathrm{dm}^{-3}$ de K; $35 \mathrm{mmol}_{\mathrm{c}} \mathrm{dm}^{-3} \mathrm{de} \mathrm{Ca}$; $12 \mathrm{mmol} \mathrm{dm}_{\mathrm{c}}^{-3} \mathrm{de} \mathrm{Mg}$; e $10 \mathrm{mmol}_{\mathrm{c}} \mathrm{dm}^{-3}$ de $\mathrm{H}+\mathrm{Al}$ e $\mathrm{V} \%$ de 82 . Com base nesta análise, foram aplicadas na área total da estrutura: 5,0 kg de sulfato de amônio; 25,0 $\mathrm{kg}$ de superfosfato simples; $15,0 \mathrm{~kg}$ de cloreto de potássio; $0,7 \mathrm{~kg}$ de sulfato de zinco; $0,35 \mathrm{~kg}$ de bórax e o composto orgânico Biomix na base de $1,5 \mathrm{~kg} \mathrm{~m}^{-2}$, sendo em seguida incorporados ao solo.

Utilizou-se no ensaio dois híbridos de berinjela: a brasileira 'Nápoli' (Agroflora/Sakata) e a japonesa 'Kokuyo' (Sumitomo Corporation do Brasil), enxertados e em pé franco, totalizando-se quatro tratamentos. $\mathrm{O}$ porta-enxerto utilizado foi o híbrido Taibyo VF, que apresenta resistência à murcha-de-verticílio e murcha-defusário, vigor e alta tolerância a baixas temperaturas.

As mudas foram produzidas em viveiro, em bandejas de poliestireno expandido de 128 células, com o substrato produzido no local: $150 \mathrm{~L}$ de terra peneirada, $50 \mathrm{~L}$ de húmus, $50 \mathrm{~L}$ de casca de arroz carbonizada, $50 \mathrm{~L}$ de esterco de curral e 1,5 kg de adubo 04-14-08. Semeou-se o porta-enxerto em 24/07/99 e quatro dias após, foram semeados os dois híbridos comerciais.

A escolha da técnica de enxertia foi baseada no melhor pegamento e na praticidade do método de enxertia de topo (Shishido et al., 1995), sendo esta realizada quando o porta-enxerto apresentava de 5 a 6 folhas totalmente expandidas e as plantas de berinjela com 4 a 5 folhas, em 04/11/99. Os porta-en- xertos foram transplantados para copos de $300 \mathrm{~mL}$ e após o pegamento, fez-se um corte longitudinal de aproximadamente $1,0 \mathrm{~cm}$ na haste do porta-enxerto. Em seguida realizou-se um corte em forma de cunha no enxerto, deixando-se 2 a 3 folhas definitivas. Estes foram fixados com clipe para enxertia, e levados para uma câmara úmida, com umidade superior a $90 \%$ e temperatura média de aproximadamente $30^{\circ} \mathrm{C}$, permanecendo neste ambiente por 13 dias fazendo-se o controle da temperatura. Após esse período, ficaram por mais 12 dias no viveiro de produção de mudas para aclimatação.

Dentro do ambiente protegido, foram feitas 4 leiras espaçadas de 1,5 m, cobertas com filme de polietileno preto com 30 micra, no espaçamento de 0,8 $\mathrm{m}$ entre plantas, onde foi feito o transplante das mudas.

Utilizou-se sistema de irrigação por gotejo (StreamLine 8 mil/Netafin, 1,49 $\mathrm{L} / \mathrm{h} / 03 \mathrm{mca}$ ), com duas linhas por canteiro. Devido às boas condições de desenvolvimento da cultura realizou-se apenas adubação potássica de cobertura, a partir do $73^{\circ}$ dia após o transplante, sendo esta realizada juntamente com a água de irrigação. Os fertilizantes foram colocados no sistema de irrigação por meio de uma bomba injetora proporcional de fertilizantes (modelo DP 30-2 DOSMATIC).

Os tratamentos fitossanitários foram realizados de acordo com a ocorrência de pragas e/ou doenças. As principais pragas observadas foram a mosca-branca (Bemisia argentifolii) e o ácaro-dobronzeamento (Aculops lycopersici).

As determinações de trocas gasosas foram realizadas com um sistema fechado portátil de fotossíntese, IRGA, modelo LI-6200 (LI-COR), sempre na região mediana de folhas novas, completamente expandidas, totalmente expostas à radiação solar, quando as plantas de berinjela se apresentavam em floração plena em um dia com ausência de nebulosidade. Determinações de assimilação líquida de $\mathrm{CO}_{2}$ (A), condutância estomática $\left(\mathrm{g}_{\mathrm{s}}\right)$ e transpiração $(\mathrm{E})$, foram feitas às 11:00 h para comparação dos híbridos em pé franco e enxertados e um acompanhamento das trocas gasosas no decorrer do dia, às 09:00; 12:00; 14:00 e 16:00 h, 
para as plantas em pé franco. Da relação entre a quantidade de $\mathrm{CO}_{2}$ assimilado por unidade de água perdida por transpiração obteve-se a eficiência do uso de água (EUA). Durante as medidas, o fluxo de fótons fotossinteticamente ativos no interior do ambiente protegido foi de $1032 \pm 87 ; 1193 \pm 119,992 \pm 209$ e $529 \pm 90$, às 09:00; 12:00; 14:00 e 16:00 $\mathrm{h}$, respectivamente.

Os dados foram submetidos à análise de variância e as médias comparadas pelo teste de Tukey a 5\% de probabilidade. Utilizou-se também análise de regressão para o ajuste dos dados de trocas gasosas durante o dia.

\section{RESULTADOS E DISCUSSÃO}

Em determinações realizadas às 11:00 h da manhã, as plantas do híbrido Kokuyo apresentaram maior assimilação líquida de $\mathrm{CO}_{2}$ quando comparadas ao híbrido Napoli, porém, a enxertia não teve influência na capacidade fotossintética de nenhum dos híbridos. (Figura 1).

A enxertia levou à menor condutância estomática (Figura 1b) e transpiração (Figura 1c) nas folhas das plantas enxertadas, sendo este efeito estatisticamente significativo. Porém, a capacidade fotossintética das plantas não foi significativamente reduzida (Figura 1a). Esta resposta resultou em maior eficiência no uso de água das plantas enxertadas, quando comparadas aos seus respectivos pés francos, para os dois híbridos em questão (Figura 1d). Segundo relatos de Wofe (1994) o aumento da eficiência do uso de água por unidade de área foliar, em função de uma queda de condutância estomática, se deve ao fluxo de vapor d'água proveniente da folha ser relativamente mais sensível que a atividade fotossintética a um fechamento parcial dos estômatos.

As causas desta resposta são discutíveis, podendo-se levantar a hipótese de efeitos do porta-enxerto ou da zona de ligação entre porta-enxerto e copa, reduzindo a condutividade hidráulica da planta, já que respostas estomáticas à produção de ácido abscísico (ABA) possivelmente são descartados, pois estas são associadas a estresses por falta d'água e salinidade. De qualquer modo,

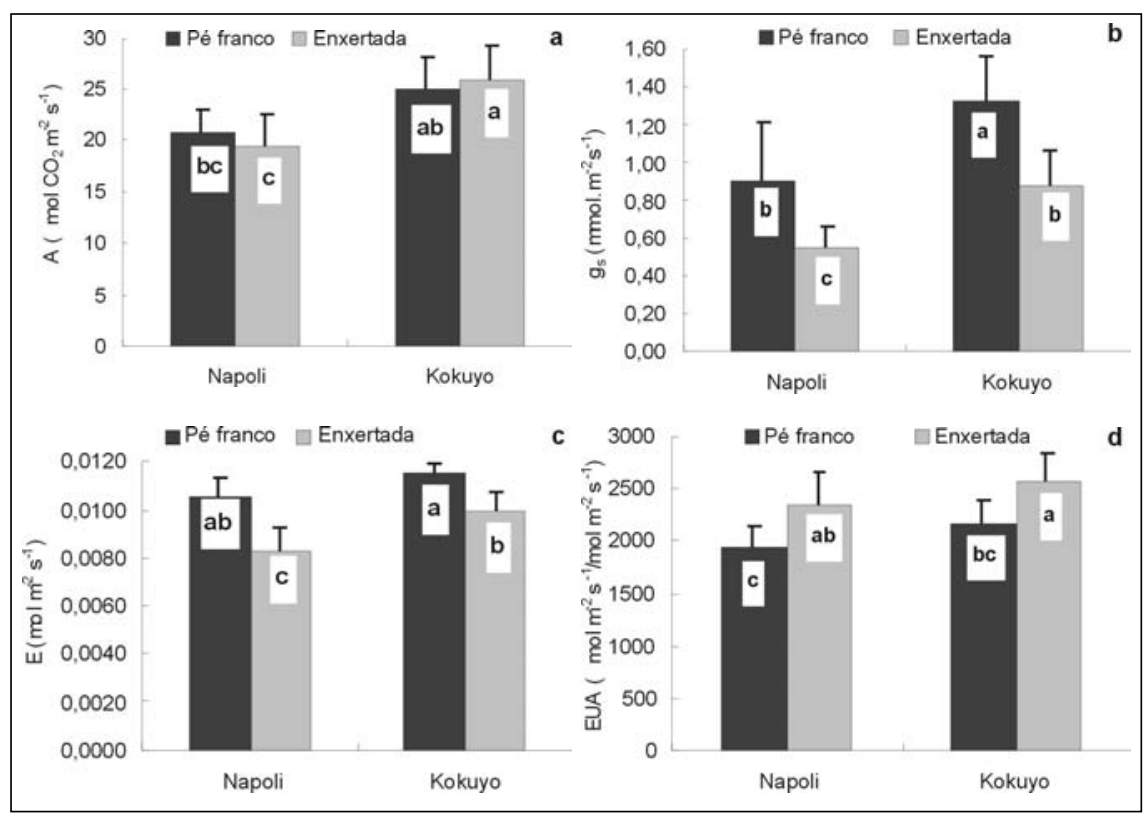

Figura 1. (a) Assimilação líquida de $\mathrm{CO}_{2}(\mathrm{~A})$, (b) Condutância estomática $\left(\mathrm{g}_{\mathrm{s}}\right)$, (c) Transpiração (E) e (d) Eficiência no uso de água (EUA) de dois híbridos de berinjela (Nápoli e Kokuyo) em pé franco e enxertados sobre porta-enxerto Taibyo VF (plantas em floração plena) $\left({ }^{*}\right.$ Letras iguais não diferem entre si pelo teste Tukey a $5 \%$ de probabilidade. Barras verticais representam o desvio padrão da média de 10 repetições). Botucatu, UNESP, 2000.

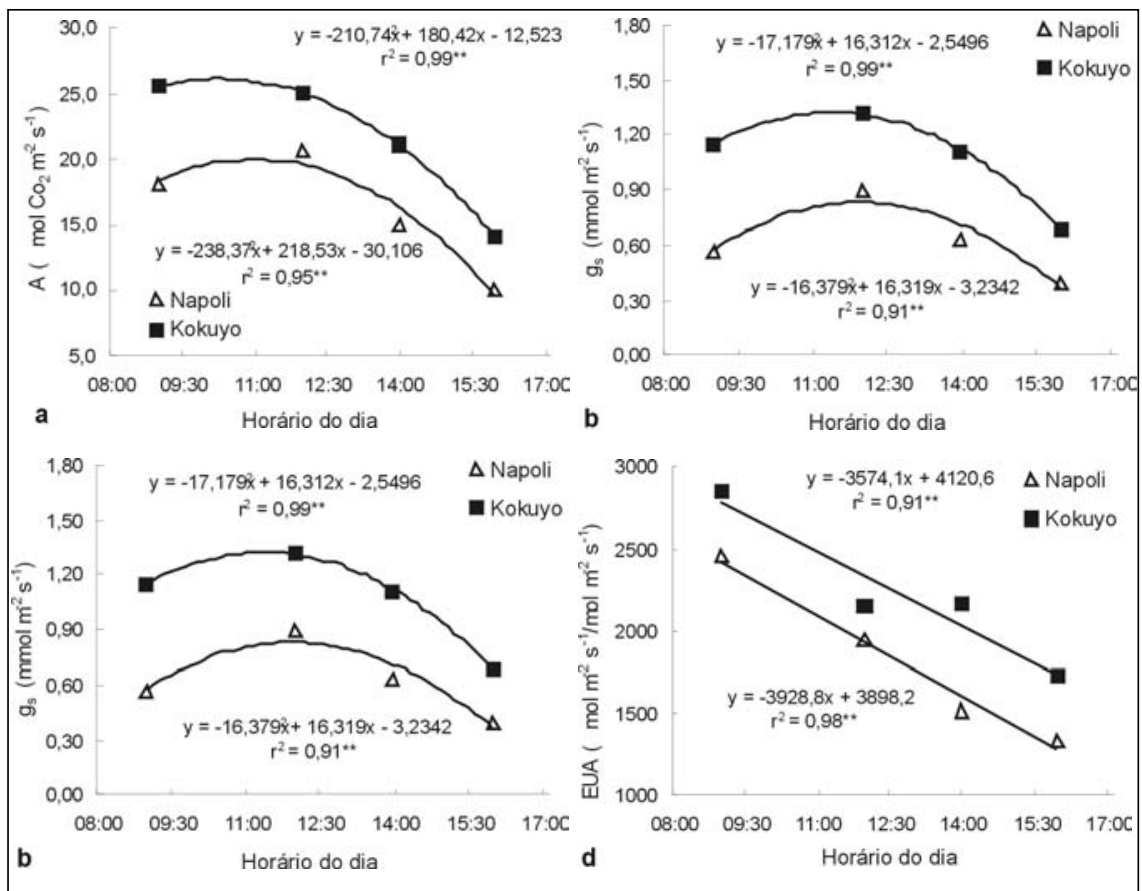

Figura 2. (a) Assimilação líquida de $\mathrm{CO}_{2}(\mathrm{~A})$, (b) condutância estomática $\left(\mathrm{g}_{\mathrm{s}}\right)$, (c) Transpiração (E) e (d) Eficiência no uso de água (EUA) de dois híbridos de berinjela (Nápoli e Kokuyo) em resposta a diferentes horários do dia, em ambiente protegido (plantas em floração plena) ${ }^{*}$ Cada ponto corresponde à média de 10 repetições. Significativo a $1 \%$ de probabilidade pelo teste T de Student). Botucatu, UNESP, 2000.

vale ressaltar que esta resposta mostrase positiva, pois poderiam resultar em maior economia de água pela planta. Portanto, estudos futuros que elucidem o efeito da enxertia na condutividade hidráulica e/ou comportamento estomático das plantas enxertadas tornam-se importantes. 
Quando foi determinado o acompanhamento das trocas gasosas durante o dia, para os dois híbridos de berinjela em pé franco, como apresentado na Figura 2, notou-se maior atividade fotossintética e condutância estomática do híbrido Kokuyo, durante todo o período de avaliação. Para a transpiração das folhas, diferenças são verificadas somente no período da manhã, quando são comparados os dois híbridos de berinjela.

Os valores de assimilação líquida de $\mathrm{CO}_{2}$ encontrados neste estudo estão de acordo com os valores máximos determinados por Kim \& Hori (1989). Estes autores ainda comentaram que a taxa fotossintética se correlacionou diretamente com o teor de clorofila das folhas, o que poderia ser um dos fatores que levaram à superioridade em taxa fotossintética do híbrido Kokuyo, pois este apresentava folhas com verde mais intenso. Estes valores são considerados altos para uma planta $\mathrm{C}_{3}$, conforme discutido por Pimentel et al. (1995).

A partir das 9:00 h, a assimilação líquida de $\mathrm{CO}_{2}$ já apresentava valores máximos para os dois híbridos, com queda a partir das $12 \mathrm{~h}$, período em que normalmente verificam-se maiores temperaturas e menor umidade relativa do ar. Estes fatores resultaram em queda gradativa e linear da eficiência no uso de água para os dois híbridos no decorrer do dia. Apesar desta queda, o híbrido Kokuyo manteve maior eficiência no uso de água durante todo o período de determinação, quando comparado ao híbrido Nápoli. Estes resultados provavelmente são devidos a um maior controle estomático observado nas horas mais quentes e secas do dia, com menores perdas de água por transpiração.

Os valores encontrados para a eficiência do uso da água em todas as avaliações realizadas estão de acordo com os valores normalmente encontrados para plantas do ciclo $\mathrm{C}_{3}$, ou seja, de 1 a $3 \mathrm{~g}$ de $\mathrm{CO}_{2}$ fixado $\mathrm{kg}^{-1}$ de água transpirada, segundo Nobel (1991), citado por Pimentel (1998).

Pode-se concluir que o híbrido de berinjela Kokuyo apresenta maiores taxas de assimilação de $\mathrm{CO}_{2}$ quando comparado ao híbrido Nápoli, podendo ser esta uma característica importante na determinação de seu potencial produtivo. A técnica de enxertia utilizada neste ensaio resultou em maior eficiência no uso de água para os dois híbridos em questão, devido à redução da condutância estomática, observada nas folhas das plantas enxertadas. Estudos futuros, relacionando características fisiológicas e anatômicas, serão importantes para elucidar as causas desta resposta estomática em função da técnica de enxertia utilizada.

\section{LITERATURA CITADA}

FOYER, C.H.; GALTIER, N. Source-sink interaction and communication in leaves. In: ZAMSKI, E; SCHAFFER,A.A. (eds.) Photoassimilate distribution in plants and crops. Source-sink relationships. New York. p. 331-340, 1996.
IKEDA, K. Effect of light intensity on the photosynthesis of vegetable crops at the seedling stage. 1. Measurement of photosynthesis and effect of leaf position and growth stage on photosynthetic rate. Journal of Agricultural Science, v. 23, n. 2, p. 118-128, 1981.

KIM, J.H.; HORI, Y. Studies on growth and photosynthetic capacity of aubergine (Solanum melongena) leaves. Journal of the Japanese Society for Horticultural Science, v. 54, n. 3, p. 371-378, 1989.

KOBORI, R.F. Controle da Murcha de Fitóftora (Phytophthora capsici) em pimentão (Capsicum annuum L.) através da enxertia. Botucatu, 1999. 138 p. (Tese doutorado), UNESP.

ODA, M. New grafting methods for fruit bearing vegetables in Japan. Japanese Agricultural Research Q, v. 29, p. 187-94, 1995.

OHARA, M.; KIYA, H.; MINEGUISHI, M.; HISATOMI, T. The effects of grafting on rootstocks on growth and yield of eggplants grown on rockwool. Bulletin of the Nara Agricultural Experiments Station, v. 21, p. 1-6, 1990.

PIMENTEL, C., LOUGUET, P., LAFFRAY, D. Trocas gasosas diurna e em quatro estádios de desenvolvimento, em Phaseolus vulgaris L., cv. Carioca. In: Resumos do V Congresso Brasileiro de Fisiologia Vegetal. UFLA-Lavras, p. 364, 1995. PIMENTEL, C., Metabolismo de carbono na agricultura tropical. Seropédica: Edur, 1998,159 p.

SANTOS, H.S.; BORGES, L.M.; CALLEGARI, O. Influência da poda na produtividade da berinjela. Horticultura Brasileira, Brasília, v. 18, p. 557-558, Suplemento, 2000.

SHISHIDO, Y.; ZHANG-XIAOLU; KUMAKURA, H.; ZHANG, X.L. Effects of rootstocks varieties, leaves and grafting conditions on scion growth in eggplant. Journal of the Japanese Society for Horticultural Science. v. 64 n. 3, p. 581-588, 1995. 